\title{
Highlights on Gold TADF Complexes
}

\author{
João Carlos Lima ${ }^{1}[$ and Laura Rodríguez $2,3, *$ (1) \\ 1 LAQV-REQUIMTE, Departamento de Química, Universidade NOVA de Lisboa, \\ 2829-516 Monte de Caparica, Portugal; lima@fct.unl.pt \\ 2 Departament de Química Inorgànica i Orgànica. Secció de Química Inorgànica. Universitat de Barcelona, \\ Martí i Franquès 1-11, 08028 Barcelona, Spain \\ 3 Institut de Nanociència i Nanotecnologia (IN²UB). Universitat de Barcelona, 08028 Barcelona, Spain \\ * Correspondence: laura.rodriguez@qi.ub.es
}

Received: 16 September 2019; Accepted: 9 October 2019; Published: 11 October 2019

check for updates

\begin{abstract}
Thermally activated delayed fluorescence (TADF) and TADF-organic light-emitting diodes (OLEDs) systems are being given increasing attention in research nowadays. Much more work has been done for organic-based materials in this field, but the use of TADF organometallic systems has also emerged in recent years. In particular, TADF-based gold compounds have not been particularly well-explored, with a higher number of examples of $\mathrm{Au}(\mathrm{I})$-molecules and fewer for the higher oxidation state $\mathrm{Au}(\mathrm{III})$ derivatives. Nevertheless, the novelty and observed results deserve attention. A careful analysis has been performed in this review by classifying the reported compounds into two different groups regarding the oxidation state of the metal, and within each group, the ancillary ligands. Specific examples to illustrate their potential applications are included in the different sections.
\end{abstract}

Keywords: gold(I); gold(III); TADF; luminescence

\section{Introduction}

Emitting materials for organic light-emitting diodes (OLEDs) have been a significant focus of academic and industrial research in recent years [1-6]. In this respect, thermally activated delayed fluorescence (TADF) represents a promising concept for harvesting both singlet and triplet excitons (Figure 1) [7-12].

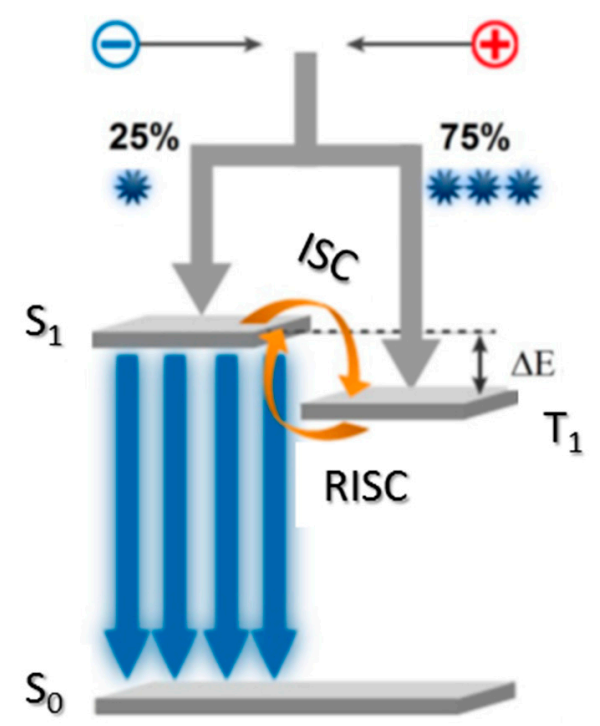

Figure 1. Schematic representation of thermally activated delayed fluorescence (TADF) process. 
As displayed in Figure 1, TADF ensures that both singlet and triplet excitons can be used for the generation of light due to intersystem crossing and small energy separation between singlet and triplet states, $\Delta \mathrm{E}_{\mathrm{ST}}$. Thermal energy allows the up-conversion from the triplet $\mathrm{T} 1$ back to singlet state $\mathrm{S} 1$ at room temperature, giving rise to TADF [7]. This process enables the use of both singlet and triplet excitons, thus exceeding the external quantum efficiency (EQE) limit of OLEDs with fluorescent materials by a factor of 4 (the spin statistic giving $25 \%$ singlet and $75 \%$ triplet excitons). In efficient TADF emitters, a small energy separation $\Delta \mathrm{E}_{\mathrm{ST}}$ between the lowest excited singlet and triplet states and a sufficient intersystem crossing (or reverse intersystem crossing, respectively) between these states enable the delayed emission.

Excellent device performance based on TADF-instead of phosphorescence-with devices exhibiting more than $20 \%$ external quantum efficiency (EQE) $[11,13]$ has been demonstrated with metal-free materials or with copper complexes [14,15]. In fact, the first metal-containing TADF material was observed in a $\mathrm{Cu}(\mathrm{I})$-complex by Blasse and co-workers in 1980 [16]. In the late 1990s, efficient delayed fluorescence was further verified in fullerenes by Berberan-Santos and co-workers, and was firstly used in the detection of oxygen and temperature [17]. Later on, the attempt to apply TADF porphyrin complexes in OLEDs emerged in 2009 by Adachi and co-workers [18]. Research on TADF OLEDs culminated in 2012, being strongly developed by the same authors $[19,20]$.

Organometallic TADF complexes are a representative kind of TADF emitters, and they have attracted significant experimental attention. Photoemission via the TADF mechanism has been found in many $\mathrm{Cu}(\mathrm{I})$ complexes and a few $\mathrm{Pd}(\mathrm{II}), \mathrm{Ag}(\mathrm{I}), \mathrm{Sn}(\mathrm{IV})$, and $\mathrm{Au}(\mathrm{I})$ complexes but are rarely reported for $\mathrm{Au}$ (III) complexes [21]. This could be because the low-energy metal centered states (MC states) can effectively quench luminescence excited states via thermal equilibration or energy transfer, thereby leading to low luminescence yields (Figure 2).

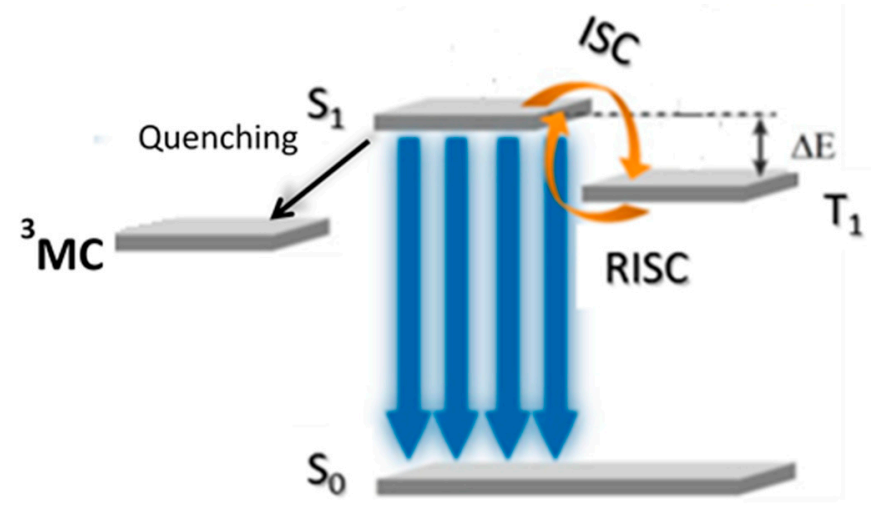

Figure 2. Schematic representation of the quenching introduced by the presence of low lying metal centred (MC) states.

Nevertheless, in the past few years, by incorporating strong $\sigma$-donating ligands into $\mathrm{Au}(\mathrm{III})$ complexes to increase $\mathrm{d}-\mathrm{d}$ states' energies, the Au(III) center has become less electrophilic, thereby resulting in the enhancement of luminescence properties [22].

In this review, the TADF properties of $\mathrm{Au}(\mathrm{I})$ and $\mathrm{Au}(\mathrm{III})$ have been summarized and organized into different groups, depending both on the oxidation state of the metal and on the ancillary ligands. In order to ensure our focus on molecular-based gold TADF materials, we have not considered nanoclustered structures, nor nanoparticle-derived complexes or heterometallic systems.

\section{Au(I) Complexes}

$\mathrm{The} \mathrm{Au}(\mathrm{I})$ compounds found in the literature that exhibit TADF have been organized in this review into two different groups, depending on whether one of their ligands is a diphosphine (Figure 3) or a carbene (Figure 6). The limited number of this type of complex displaying delayed fluorescence, DF, is due to the well-known aurophilicity $(\mathrm{Au}(\mathrm{I}) \cdots \mathrm{Au}(\mathrm{I})$ interactions). This particular property modulates 
the energy of excited states while retaining the coordination sphere and is capable of considerably affecting the photophysical properties of the di- or polymetallic molecules [23]. In this way, polynuclear aurophilic complexes present a stronger spin-orbit coupling (SOC) effect, resulting in triplet state population and phosphorescence emission. For this reason, a priori, it is not expected that $\mathrm{Au}(\mathrm{I})$ compounds present TADF properties. However, there are other reasons that affect this process and in 2013 it was reported by Osawa and collaborators what it was considered to be the first $\mathrm{Au}(\mathrm{I})$ complex displaying TADF (compound 1, Figure 3) [24], the compound Au(PP)(PS) complex (PP = 1,2-bis(diphenylphosphino)benzene and PS = 2-diphenylphosphinobenzenethiolate) on the basis of emission characteristics measured at 298 and $77 \mathrm{~K}$. It possesses tetrahedral geometry and exhibits orange emission in solution around $600 \mathrm{~nm}$, ca. $100 \mathrm{~nm}$ red-shifted with respect to the analogous copper(I) and silver(I) complexes. The thiolate ligand with electron-donating character ( $\left.\mathrm{PS}^{-}\right)$reduced the contribution of metal orbitals to the HOMOs of the complexes, decreasing the metal to ligand charge transfer, MLCT, character of their excited states. As a result, the origin of the TADF was a ligand-ligand charge transfer LLCT transition. Although it has been considered the first example of $\mathrm{Au}(\mathrm{I}) \mathrm{TADF}$ complexes reported in the literature [25], it should be noted that three years earlier, the same author reported the anomalous long-lived emission from complex $\mathbf{2}$ at room temperature and it was assumed to be E-type delayed fluorescence (TADF) [26]. Additionally, it was observed that the counter anion governs the photophysical properties of the cationic complex 2 through intermolecular interactions in a crystalline state, with a red-shift of ca. $70 \mathrm{~nm}$ from chloride to $\left.\mathrm{B}_{(} \mathrm{C}_{6} \mathrm{H}_{4} \mathrm{~F}-4\right)_{4}$ with the

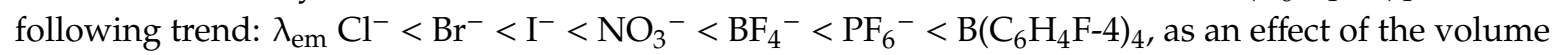
of the anion and location in the crystalline packing, to a greater or lesser extent, affecting the geometry of the cationic $\left[\mathrm{Au}(\mathrm{L})_{2}\right]^{+}(\mathrm{L}=$ diphosphine) counterpart. According to DFT calculations, a distortion of the perfect tetrahedron corresponding to the cationic complex is associated with an increase of the energy difference $\Delta \mathrm{E}_{\mathrm{D}}$, between the HOMO and HOMO-1 (which are degenerated in a perfect tetrahedral symmetry) and thus, to a decrease of the HOMO-LUMO energy gap [26]. In this way, $\Delta \mathrm{E}_{\mathrm{D}}$ may be considered as an index for the evaluation of the distortion from tetrahedral symmetry. 


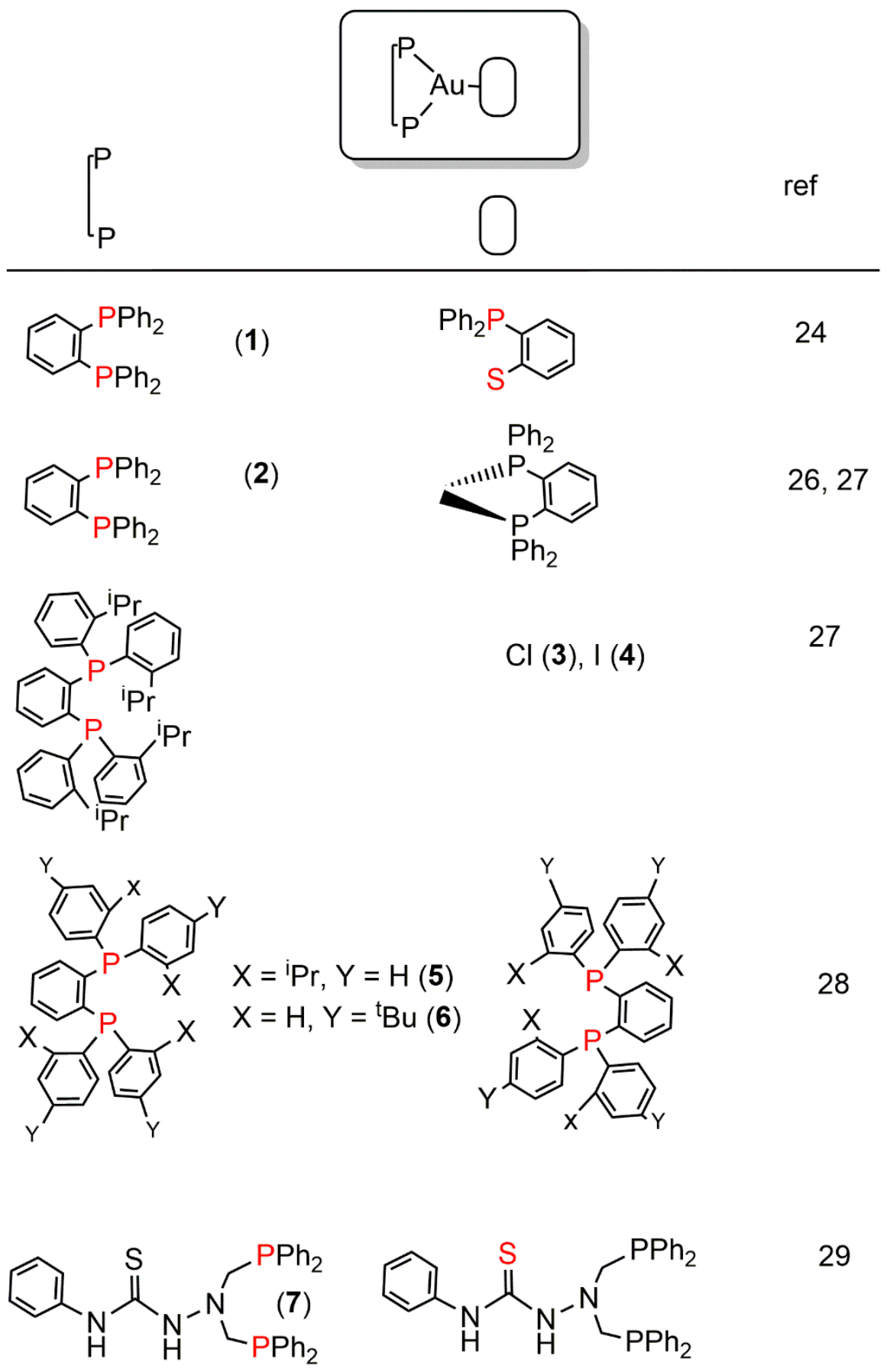

Figure 3. Chemical structure of diphosphine- $\mathrm{Au}(\mathrm{I})$ derivatives that display TADF properties. Coordinating atoms are marked in red.

The bulkiness of the diphosphine ligands present in compounds $\mathbf{3} \mathbf{- 5}$ are responsible for the coordination number of 3 in these complexes, since analogous synthesis performed with less bulky diphosphine gives rise to the formation of the dinuclear (diphos) $(\mathrm{AuCl})_{2}$ compounds [27]. Theoretical calculations, in agreement with experimental data, show that the recorded absorption bands are mainly dominated by the HOMO-LUMO transitions, where the HOMO is mainly based on the phosphine ligands, with very low contributions of the halogen atoms. Emission maxima and luminescence lifetimes recorded for 3 and 4 are observed to depend on the temperature in agreement with the TADF behavior (Figure 4). 

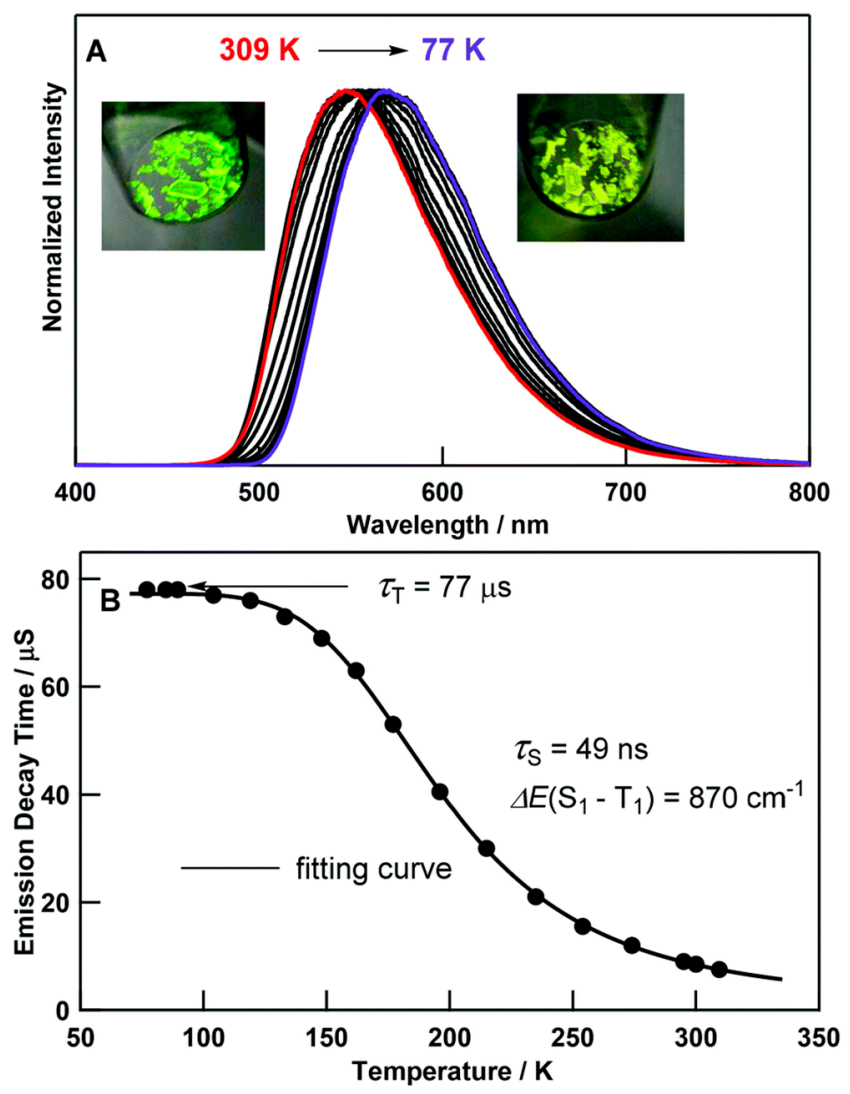

Figure 4. Temperature-dependent change of: (A) corrected emission spectra and (B) emission decay times for $4 ; \lambda_{\text {exc }}=355 \mathrm{~nm}$. Inset: Luminescence image of 4 at 309 and $77 \mathrm{~K} ; \lambda_{\text {exc }}=365 \mathrm{~nm}$. Reproduced with permission from Osawa, M. et al., Dalton Trans.; published by Royal Society of Chemistry, 2018 [27].

Very recent publications by the same group display the TADF behavior of bis(diphosphine) gold(I) derivatives 5 [27] and 6 [28] with stronger luminescence properties in the solid state with respect to solution. This fact was attributed to the "pseudo Jahn-Teller effect" occurring in the excited state, and was supported by quantum chemical calculations that predict the structural change of 5 from tetrahedral to flattened geometry in the excited state.

Interestingly, compounds 3-5 display near unity TADF in the crystalline state. On the other hand, the analogous bis(diphosphine) compound 6. $\mathrm{Cl}$ displays both TADF and phosphorescence emission. The T1 state responsible for emission is composed of metal-centered $\left({ }^{3} \mathrm{MC}\right)$ and ligand-to-metal charge-transfer $\left({ }^{3} \mathrm{LMCT}\right.$ : from the P atoms to the metal) states [28]. Recrystallization of a THF solution of 6. $\mathrm{Cl}$ in different poor solvents (alkanes) demonstrates an interesting vapochromism due to the empty cavities observed in the X-ray crystal structure of the molecule. X-ray crystal structure resolution shows that two $6^{+}$cations sandwich the $n$-alkane (hexane) molecule at both ends via $\mathrm{CH} / \pi$ interactions, and that the THF molecule has an intermolecular $\mathrm{CH} / \pi$ interaction with one bridged phenylene unit of the diphosphine (Figure 5). 

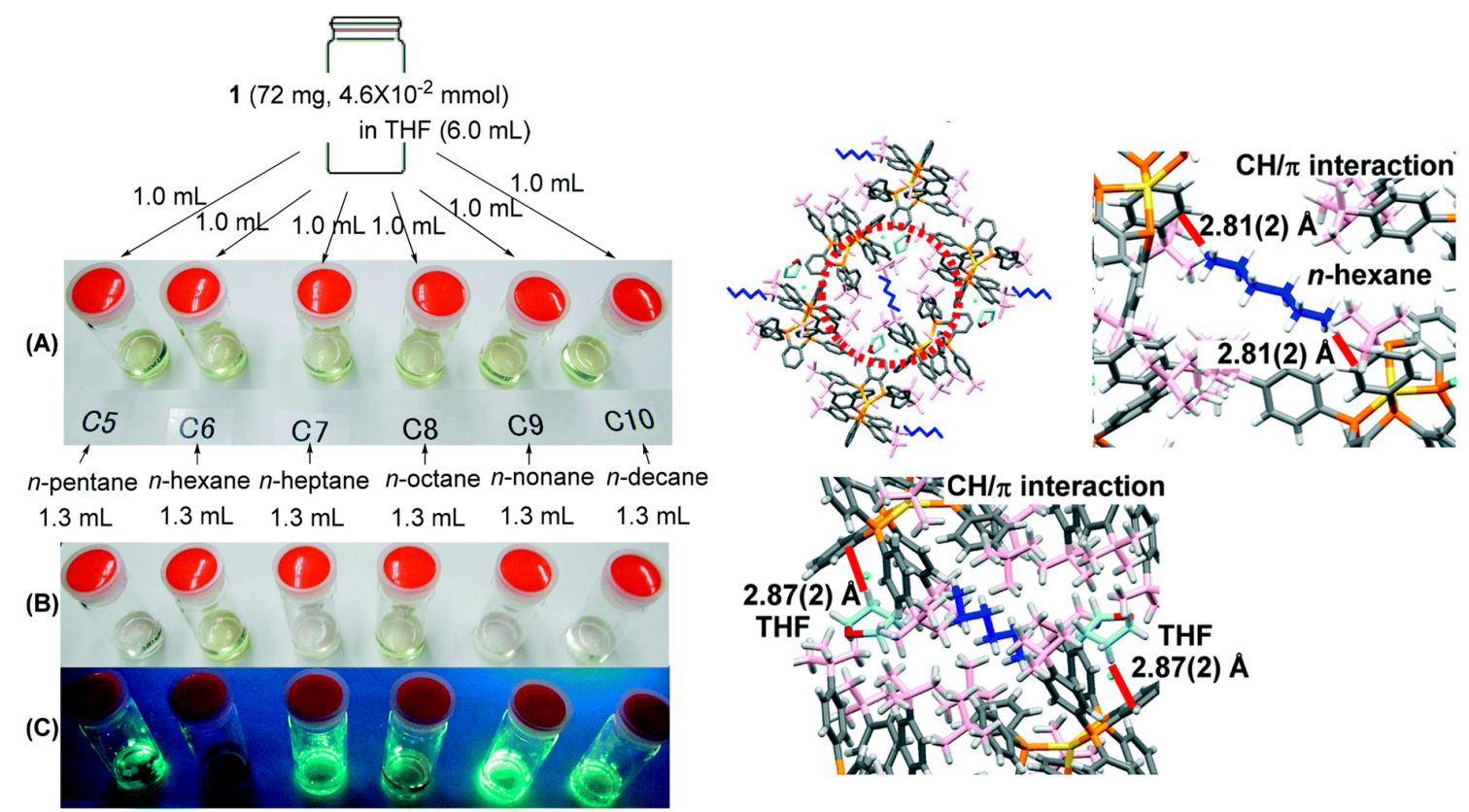

Figure 5. (Left) Recrystallization procedure with THF and alkanes: (A) image of the solutions just after alkane addition; (B) image of the solutions after $12 \mathrm{~h}$; and (C) emission images; $\lambda_{\text {exc }}=365 \mathrm{~nm}$. (Right) Packing view (100) of 6 recrystallized from THF/hexane. Magnified view of the $\mathrm{CH} \cdots \pi$ interactions (red lines) between n-hexane and $\mathbf{6}^{+}$(two THF molecules and two 4-tert-butylphenyl groups are omitted for clarity) and magnified view of the $\mathrm{CH} \cdots \pi$ interactions (red lines) between THF and $\mathbf{6}^{+}$. Reproduced with permission from Osawa, M. et al., Dalton Trans.; published by Royal Society of Chemistry, 2019 [28].

The demonstration that this is a field increasing in interest and starting to be explored by other groups comes from a very recent publication in 2019, from the group of J.-P. Lang and collaborators [29], with the preparation and study of a P-S multifunctional dinuclear $\mathrm{Au}(\mathrm{I})$ complex 7 . The ligand bridges two $\mathrm{Au}(\mathrm{I})$ centers, and each $\mathrm{Au}(\mathrm{I})$ is tetrahedrally coordinated by two $\mathrm{P}$ atoms and two bridging $\mathrm{S}$ atoms from two ligands that form the central, centrosymmetric $\left[\mathrm{Au}_{2} \mathrm{~S}_{2} \mathrm{P}_{4}\right]$ rhombus. In this case, aurophilic interactions do not affect the resulting luminescent properties since the $\mathrm{Au} \cdots \mathrm{Au}$ distance is $4.170 \AA$ A. A linear decrease of the Au-S bond length with temperature was associated with an increase of the luminescence intensity, therefore being a promising tool for fine luminescence tuning. This was attributed to crystal packing effects, although possible delayed fluorescence cannot be discarded. The compound also displays solvatochromism behavior and it was observed that solvents containing $\mathrm{H}_{2} \mathrm{O}$ and alcohol led to shorter Au-S distances in the solid-state and therefore to enhanced luminescence, which is also promising in sensing processes.

Carbene gold(I)-L ( $\mathrm{L}=\mathrm{N}$-donor ligand such as amine or carbazole) complexes that display luminescence have been studied for a range of applications, but mainly in terms of OLEDs. Interesting results in this field were reported by D. Di and co-workers, with compounds 8-10 (Figure 6) [30]. Time-resolved electroluminescence (EL) measurements show that emission occurs entirely via a sub- $\mu \mathrm{s}$ delayed-emission channel and that there is no prompt (ns) component that would usually distinguish between geminate singlets and triplets. Transient photoluminescence (PL) and absorption (TA) spectra of spin-cast films were measured to understand the emission mechanism of the compounds. All compounds show a $<1$ ns prompt-photoluminescence component, and a delayed component, the lifetime of which is strongly temperature-dependent, in agreement with TADF. 

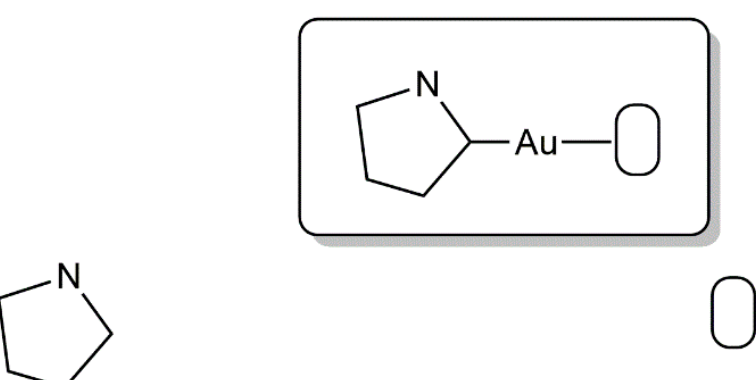

ref
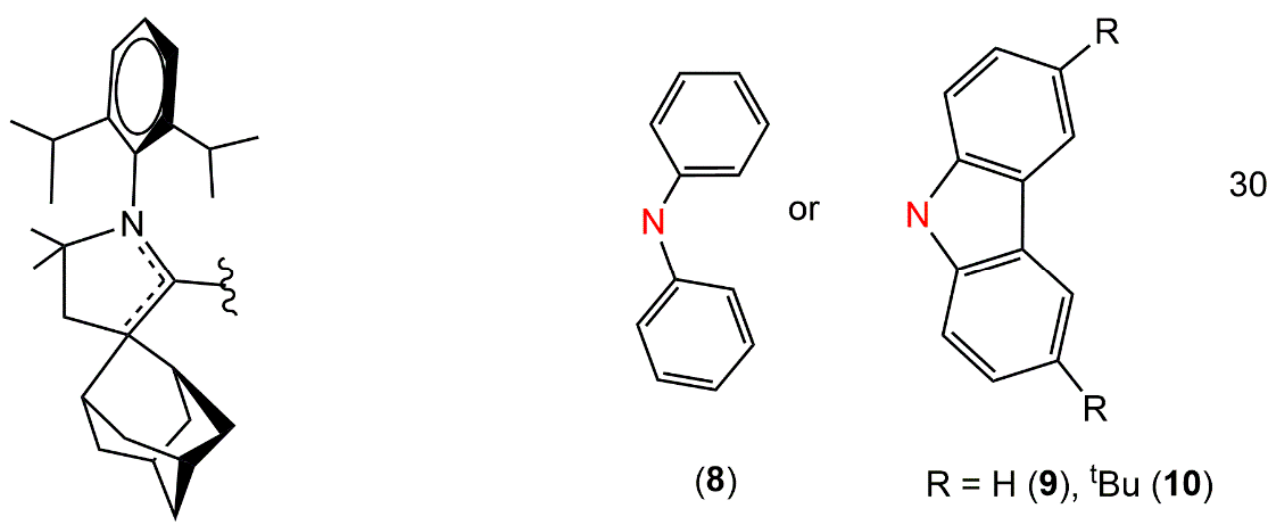

(8)

$\mathrm{R}=\mathrm{H}(\mathbf{9}),{ }^{\mathrm{t}} \mathrm{Bu}(\mathbf{1 0})$<smiles>CC[C@H]1CC(C)CC[C@@H]1C</smiles><smiles>CC1(C)CN(C(=O)OCc2ccccc2)CN(C2CCCCC2)C1=O</smiles><smiles>c1ccc2c(c1)[nH]c1ccccc12</smiles>

dipp $=$ 2,6-diisopropylphenyl

Figure 6. Chemical structure of carbine-Au(I) derivatives that display TADF properties. Coordinating atoms are marked in red.

Detailed temperature-dependent photophysical measurements (5-325 K) were carried out for 11 and 12 to determine the singlet and triplet emission lifetimes $\left(\tau_{\mathrm{fl}}\right.$ and $\left.\tau_{\mathrm{ph}}\right)$ and the energy are around $1 \mu \mathrm{s}$ in toluene at room temperature and in the 40-300 $\mu$ s regime at $77 \mathrm{~K}$. The emission at room temperature is due exclusively to E-type delayed fluorescence or TADF difference between the singlet and triplet excited state, $\triangle \mathrm{ES1} 1 \mathrm{~T} 1$. This value is similar for their analogous copper complexes, but larger than the value recorded for the isoelectronic silver derivatives [31]. Detailed photophysical studies together with theoretical calculations performed by the authors demonstrate that the rate of emission of the compounds via thermally enhanced luminescence, i.e., $\mathrm{T} 1 \rightarrow \mathrm{S} 1 \rightarrow \mathrm{S} 0+\mathrm{h} v$, is controlled not by the ISC rates between $\mathrm{T} 1$ and $\mathrm{S} 1$, nor by $\mathrm{k}_{\mathrm{fl}}$ and $\mathrm{k}_{\mathrm{ph}}$ from the respective $\mathrm{S} 1$ and $\mathrm{T} 1$ states, but is fully governed by $\Delta \mathrm{E}_{\mathrm{S} 1-\mathrm{T} 1}$.

\section{Au(III) Complexes}

The structural properties of $\mathrm{Au}(\mathrm{III})$ complexes are completely different from $\mathrm{Au}(\mathrm{I})$ since they present square planar geometry and their $\mathrm{d}^{8}$ electronic configuration gives them different photophysical properties. 
Manfred Bochmann and co-workers were the first group that reported $\mathrm{Au}(\mathrm{III})$ complexes as TADF emitters [32]. They synthesized pyrazine-based Au(III) pincer complexes (compounds 13-20, Figure 7) via a new synthesis route with mercuration of the pro-ligand, transmetallation with $\mathrm{KAuCl}_{4}$ and different substitutions of the chloride afterwards. The resulting cyclometallated gold(III) pincer complexes provide a new family of photoluminescent compounds which allow for facile modulation of the emission characteristics by protonation, alkylation, Lewis acids or metal ions, without the need for modifying the pincer ligand framework (Figure 8). The modulation arises from the coexistence of high energy TADF and ${ }^{3} \mathrm{IL}\left(\mathrm{C}^{\wedge} \mathrm{N}^{\mathrm{pz}}{ }^{\wedge} \mathrm{C}\right){ }^{\beta} \mathrm{LLCT}\left(\mathrm{X} \rightarrow \mathrm{C}^{\wedge} \mathrm{N}^{\mathrm{pz}} \mathrm{C}\right)$ transitions.
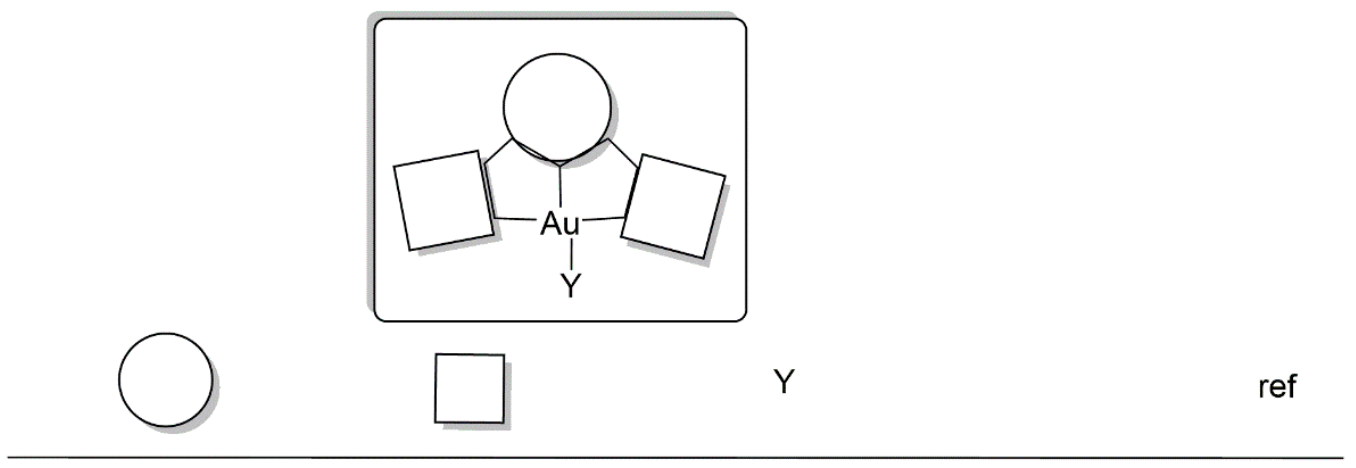<smiles>[R]c1ccncc1</smiles><smiles>CCc1ccccc1C</smiles><smiles>Cc1ccccc1I</smiles><smiles>CCOc1ccncc1</smiles><smiles>c1ccc2cnccc2c1</smiles><smiles>Cc1cccc(C)c1-c1ccncc1</smiles><smiles>Fc1cc(F)c(I)c(I)c1</smiles><smiles>c1ccncc1</smiles><smiles>Cc1ccccc1C</smiles><smiles>Cc1ccc(C(C)(C)C)cc1I</smiles>

$$
\begin{aligned}
& X=C ; R=H(13) \text {, alkyl (14), aryl (15) } \\
& X=N, R=H(16), \text { alkyl (17), aryl (18) } \\
& X=N ; R=-, R^{\prime}=P h(19),{ }^{t} \mathrm{Bu}(20)
\end{aligned}
$$$$
\mathrm{X}=\mathrm{N}, \mathrm{R}=\mathrm{H} \text { (16), alkyl (17), aryl (18) }
$$<smiles>c1ccc2c(c1)[nH]c1ccccc12</smiles><smiles>[Z]c1ccc(C)cc1</smiles><smiles>Cc1ccc(N(c2ccccc2)c2ccccc2)cc1</smiles>

(27)<smiles>CC(C)(C)c1ccc(N(c2ccc(C(C)(C)C)cc2)c2ccc(C(N)(F)F)cc2)cc1</smiles>

Figure 7. Chemical structure of $\mathrm{Au}(\mathrm{III})$ complexes that display TADF properties. Coordinating atoms are marked in red. 
A
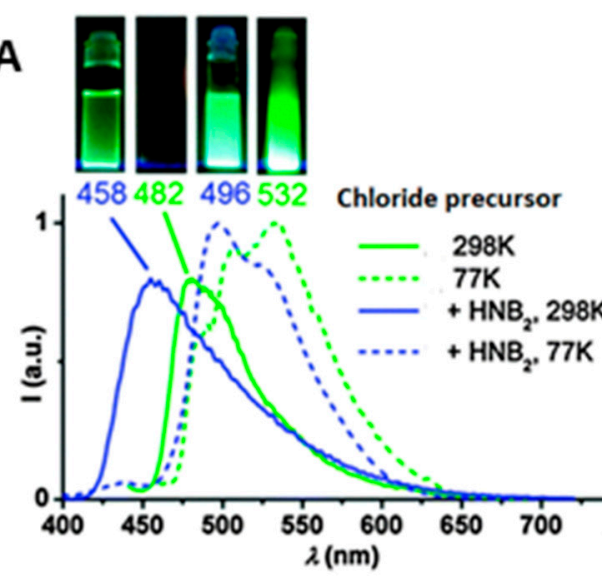

5a $+\mathrm{ZnCl}_{2} \mathrm{CdCl}_{2} \quad \mathrm{HgCl}_{2}$

C
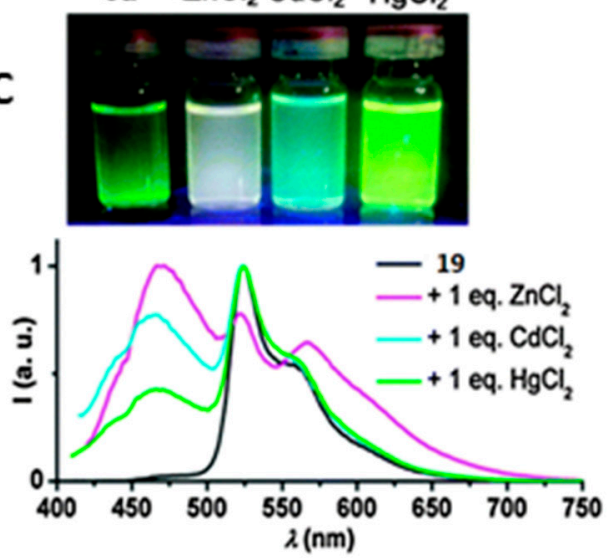

10 eq. 5 eq. 1 eq. 0.5 eq. $5 a$

B
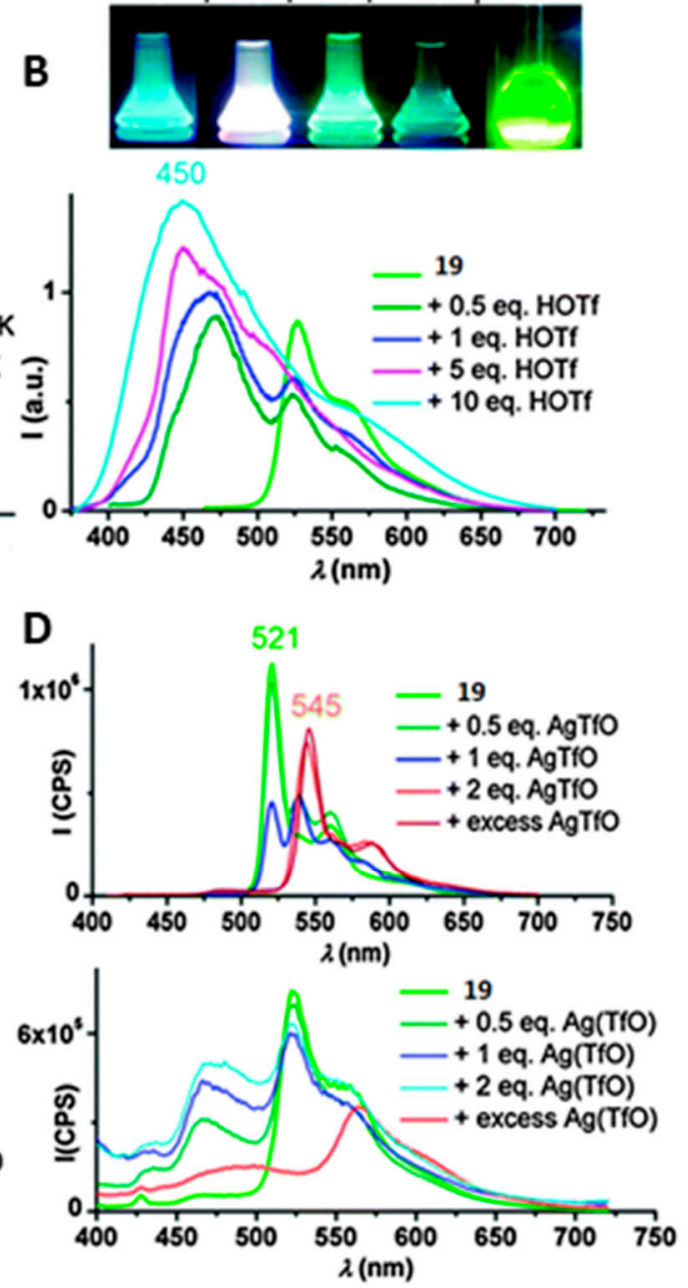

Figure 8. (A) Prompt luminescence, PL, of chloride precursor of $19\left(\mathrm{CH}_{2} \mathrm{Cl}_{2}, 1 \times 10^{-4} \mathrm{M}\right)$ in the absence and presence of two equivalents of $\left[\mathrm{H}\left(\mathrm{OEt}_{2}\right)_{2}\right]\left[\mathrm{H}_{2} \mathrm{~N}\left\{\mathrm{~B}\left(\mathrm{C}_{6} \mathrm{~F}_{5}\right)_{3}\right\}_{2}\right]\left(\mathrm{HNB}_{2}\right)$ at 298 and $77 \mathrm{~K}$. (B) PL response of $19\left(\mathrm{CH}_{2} \mathrm{Cl}_{2}, 1 \times \cdot 10^{-4} \mathrm{M}\right)$ to the addition of HOTf at $298 \mathrm{~K}$. (C) PL of mixtures of 19 with equimolar amounts of $\mathrm{MCl}_{2}(\mathrm{M}=\mathrm{Zn}, \mathrm{Cd}, \mathrm{Hg})$ in THFMe-2 ([19] $\left.=1 \times 10^{-4} \mathrm{M}\right)$ at $298 \mathrm{~K}$. (D) PL response of $5 \mathrm{a}$ (THFMe-2, $5 \times 10^{-4} \mathrm{M}$ ) to the addition of AgOTf at 77 (top) and $298 \mathrm{~K}$ (bottom). Reproduced with permission from Fernandez-Cestau, J. et al., Chem. Commun. published by Royal Society of Chemistry, 2015 [32].

Two years later, C.-M. Che and co-workers reported a series of $\mathrm{Au}(\mathrm{III})$ cyclometallated complexes containing a substituted aryl ligand at the auxiliary position (compounds 21-28, Figure 6) [33]. X-ray crystal data showed that the aryl ligand is not coplanar with the $\mathrm{C}^{\wedge} \mathrm{N}^{\wedge} \mathrm{C}$ ligand plane, forming a dihedral angle of 49.80-68.088. All these complexes display photoluminescence in solutions at room temperature with two different profiles in degassed toluene: 22 and $\mathbf{2 3}$ show broad, structureless emission bands with short lifetimes ( $\lambda_{\max }=534$ and $596 \mathrm{~nm}$, and $\tau=1.03$ and $0.32 \mu \mathrm{s}$, respectively), while 21 and 24 exhibit vibronically structured emission bands with long lifetimes $\left(\lambda_{\max }=468-534 \mathrm{~nm}\right.$; $\tau=61.5$ and $43.5 \mu$ s, respectively), which strongly suggests that their emissions are of different origins. The corresponding emissions were assigned to LLCT arising from the electronic transition from the $\pi$ orbital of the amino-substituted aryl ligand to the $\pi^{*}$ orbital of the $\mathrm{C}^{\wedge} \mathrm{N}^{\wedge} \mathrm{C}$ ligand and to ${ }^{3} \mathrm{IL}$ transitions of the $\mathrm{C}^{\wedge} \mathrm{N}^{\wedge} \mathrm{C}$ ligand respectively. Emissions were also recorded in all cases in PMMA thin films $(4 \% w t)$ with similar profiles to those previously recorded in toluene. Calculation of $k_{\mathrm{r}}$ constants, and assuming a Boltzmann equilibrium between the $\mathrm{S} 1$ and $\mathrm{T} 1$ excited states, the authors conclude that the compounds present TADF behavior. 
This effect was verified by recording emission spectra and lifetimes at different temperatures. Interestingly, the compounds were successfully used in the fabrication of OLEDs showing record-high maximum EQE and luminance of up to $23.8 \%$ and $57,340 \mathrm{~cd} \cdot \mathrm{m}^{-2}$, as well as EQEs of up to $16.5 \%$ at $1000 \mathrm{~cd} \cdot \mathrm{m}^{-2}$, clearly establishing the practical usefulness of $\mathrm{Au}(\mathrm{III})-\mathrm{TADF}$ emitters in OLED technology.

\section{Conclusions and Outlook}

TADF-Au(I) based compounds are strongly influenced by the presence of aurophilic contacts, since this particular property modulates the energy of the excited states while retaining the coordination sphere, and is capable of considerably affecting the photophysical properties. Other parameters such as counterion also affect this process. In fact, according to DFT calculations, it seems that the observed TADF-dependence is correlated with the difference between the HOMO and HOMO- $1\left(\Delta \mathrm{E}_{\mathrm{D}}\right)$ and thus, to a decrease of the HOMO-LUMO energy gap.

$\mathrm{Au}(\mathrm{I}) \mathrm{TADF}$ materials reported in the literature contain phosphine or carbene ligands.

Fewer examples are reported for $\mathrm{Au}(\mathrm{III})$-based molecules with respect to $\mathrm{Au}(\mathrm{I})$ and the majority are cyclometalled compounds. The successful fabrication of OLEDs showing record-high maximum EQE and luminance clearly establish the practical usefulness of $\mathrm{Au}(\mathrm{III})$-TADF emitters in OLED technology.

All in all, this review shows that gold luminescent complexes are still not extensively used as TADF emitters. Nevertheless, their very well-established synthetic methods, together with their interesting luminescent properties, make the authors confident to start increasing their research interest in this field. Although the major number of examples contain $\mathrm{Au}(\mathrm{I})$ ions in their structure, the very promising results recorded for cyclometallated $\mathrm{Au}(\mathrm{III})$ complexes included in OLEDs fabrication, shows the potential of square-planar complexes as TADF emissive materials.

Funding: This research received no external funding.

Acknowledgments: The authors are grateful to Spanish Ministerio de Ciencia, Innovación y Universidades (AEI/FEDER, UE Project CTQ2016-76120-P). FCT/MCTES is acknowledged for financial support through the Associate Laboratory for Green Chemistry, LAQV-REQUIMTE (UID/QUI/50006/2013) and through Project PTDC/QUI-QFI/32007/2017.

Conflicts of Interest: The authors declare no conflict of interest.

\section{References}

1. Pashaei, B.; Karimi, S.; Shahroosvand, H.; Abbasi, P.; Pilkington, M.; Bartolotta, A.; Fresta, E.; Fernandez-Cestau, J.; Costa, R.D.; Bonaccorso, F. Polypyridyl ligands as a versatile platform for solid-state light-emitting devices. Chem. Soc. Rev. 2019, 48, 5033-5139. [CrossRef]

2. Cai, M.; Zhang, D.; Duan, L. High Performance Thermally Activated Delayed Fluorescence Sensitized Organic Light-Emitting Diodes. Chem. Rec. 2019, 19, 1611-1623. [CrossRef] [PubMed]

3. Wang, X.; Wang, S. Phosphorescent Pt(II) Emitters for OLEDs: From Triarylboron-Functionalized Bidentate Complexes to Compounds with Macrocyclic Chelating Ligands. Chem. Rec. 2019, 19, 1693-1709. [CrossRef] [PubMed]

4. Lian, H.; Shen, J.; Guo, H.; Cheng, X.; Dong, Q.; Yang, J.; Wong, W. Recent Advances in the Optimization of Organic Light-Emitting Diodes with Metal-Containing Nanomaterials. Chem. Rec. 2019, 19, 1753-1767. [CrossRef] [PubMed]

5. Zampetti, A.; Minotto, A.; Cacialli, F. Near-Infrared (NIR) Organic Light-Emitting Diodes (OLEDs): Challenges and Opportunities. Adv. Funct. Mater. 2019, 29, 1807623. [CrossRef]

6. Zhang, Q.C.; Xiao, H.; Zhang, X.; Xu, L.J.; Chen, Z.N. Luminescent oligonuclear metal complexes and the use in organic light-emitting diodes. Coord. Chem. Rev. 2019, 378, 121-133. [CrossRef]

7. Bergmann, L.; Zink, D.M.; Bräse, S.; Baumann, T.; Volz, D. Metal-Organic and Organic TADF-Materials: Status, Challenges and Characterization. Top. Curr. Chem. 2016, 374, 22. [CrossRef]

8. Wei, Q.; Ge, Z.; Voit, B. Thermally Activated Delayed Fluorescent Polymers: Structures, Properties, and Applications in OLED Devices. Macromol. Rapid Commun. 2019, 40, 1800570. [CrossRef] 
9. Lee, J.H.; Chen, C.H.; Lee, P.H.; Lin, H.Y.; Leung, M.; Chiu, T.L.; Lin, C.F. Blue organic light-emitting diodes: Current status, challenges, and future outlook. J. Mater. Chem. C 2019, 7, 5874-5888. [CrossRef]

10. Zou, Y.; Gong, S.; Xie, G.; Yang, C. Design Strategy for Solution-Processable Thermally Activated Delayed Fluorescence Emitters and Their Applications in Organic Light-Emitting Diodes. Adv. Opt. Mater. 2018, 6, 1800568. [CrossRef]

11. Jankus, V.; Data, P.; Graves, D.; McGuinness, C.; Santos, J.; Bryce, M.R.; Dias, F.B.; Monkman, A.P. Highly Efficient TADF OLEDs: How the Emitter-Host Interaction Controls Both the Excited State Species and Electrical Properties of the Devices to Achieve Near 100\% Triplet Harvesting and High Efficiency. Adv. Funct. Mater. 2014, 24, 6178-6186. [CrossRef]

12. Huang, T.; Jiang, W.; Duan, L. Recent progress in solution processable TADF materials for organic light-emitting diodes. J. Mater. Chem. C 2018, 6, 5577-5596. [CrossRef]

13. Zhang, Q.; Tsang, D.; Kuwabara, H.; Hatae, Y.; Li, B.; Takahashi, T.; Lee, S.Y.; Yasuda, T.; Adachi, C. Nearly $100 \%$ internal quantum efficiency in undoped electroluminescent devices employing pure organic emitters. Adv. Mater. 2015, 27, 2096-2100. [CrossRef] [PubMed]

14. Volz, D.; Chen, Y.; Wallesch, M.; Liu, R.; Fléchon, C.; Zink, D.M.; Friedrichs, J.; Flügge, H.; Steininger, R.; Göttlicher, J.; et al. Bridging the Efficiency Gap: Fully Bridged Dinuclear Cu(I)-Complexes for Singlet Harvesting in High-Efficiency OLEDs. Adv. Mater. 2015, 27, 2538-2543. [CrossRef] [PubMed]

15. Deaton, J.C.; Switalski, S.C.; Kondakov, D.Y.; Young, R.H.; Pawlik, T.D.; Giesen, D.J.; Harkins, S.B.; Miller, A.J.M.; Mickenberg, S.F.; Peters, J.C. E-Type Delayed Fluorescence of a Phosphine-Supported $\mathrm{Cu}_{2}\left(\mu-\mathrm{NAr}_{2}\right)_{2}$ Diamond Core: Harvesting Singlet and Triplet Excitons in OLEDs. J. Am. Chem. Soc. 2010, 132, 9499-9508. [CrossRef] [PubMed]

16. Blasse, G.; Mcmillin, D.R. On the luminescence of bis (triphenylphosphine) phenanthroline copper(I). Chem. Phys. Lett. 1980, 70, 1-3. [CrossRef]

17. Berberan-Santos, M.N.; Garcia, J.M.M. Unusually Strong Delayed Fluorescence of C 70. J. Am. Chem. Soc. 1996, 118, 9391-9394. [CrossRef]

18. Endo, A.; Ogasawara, M.; Takahashi, A.; Yokoyama, D.; Kato, Y.; Adachi, C. Thermally Activated Delayed Fluorescence from $\mathrm{Sn}^{4+}$-Porphyrin Complexes and Their Application to Organic Light Emitting Diodes-A Novel Mechanism for Electroluminescence. Adv. Mater. 2009, 21, 4802-4806. [CrossRef]

19. Uoyama, H.; Goushi, K.; Shizu, K.; Nomura, H.; Adachi, C. Highly efficient organic light-emitting diodes from delayed fluorescence. Nature 2012, 492, 234-238. [CrossRef]

20. Tao, Y.; Yuan, K.; Chen, T.; Xu, P.; Li, H.; Chen, R.; Zheng, C.; Zhang, L.; Huang, W. Thermally Activated Delayed Fluorescence Materials towards the Breakthrough of Organoelectronics. Adv. Mater. 2014, 26, 7931-7958. [CrossRef]

21. Gao, Y.J.; Chen, W.K.; Zhang, T.T.; Fang, W.H.; Cui, G. Theoretical Studies on Excited-State Properties of $\mathrm{Au}(\mathrm{III})$ Emitters with Thermally Activated Delayed Fluorescence. J. Phys. Chem. C 2018, 122, 27608-27619. [CrossRef]

22. To, W.P.; Chan, K.T.; Tong, G.S.M.; Ma, C.; Kwok, W.M.; Guan, X.; Low, K.H.; Che, C.M. Strongly Luminescent Gold(III) Complexes with Long-Lived Excited States: High Emission Quantum Yields, Energy Up-Conversion, and Nonlinear Optical Properties. Angew. Chem. Int. Ed. 2013, 52, 6648-6652. [CrossRef] [PubMed]

23. Belyaev, A.; Eskelinen, T.; Dau, T.M.; Ershova, Y.Y.; Tunik, S.P.; Melnikov, A.S.; Hirva, P.; Koshevoy, I.O. Cyanide-Assembled $\mathrm{d}^{10}$ Coordination Polymers and Cycles: Excited State Metallophilic Modulation of Solid-State Luminescence. Chem. A Eur. J. 2018, 24, 1404-1415. [CrossRef] [PubMed]

24. Osawa, M.; Kawata, I.; Ishii, R.; Igawa, S.; Hashimoto, M.; Hoshino, M. Application of neutral d ${ }^{10}$ coinage metal complexes with an anionic bidentate ligand in delayed fluorescence-type organic light-emitting diodes. J. Mater. Chem. C 2013, 1, 4375-4383. [CrossRef]

25. Bizzarri, C.; Hundemer, F.; Busch, J.; Bräse, S. Triplet emitters versus TADF emitters in OLEDs: A comparative study. Polyhedron 2018, 140, 51-66. [CrossRef]

26. Osawa, M.; Kawata, I.; Igawa, S.; Hoshino, M.; Fukunaga, T.; Hashizume, D. Vapochromic and Mechanochromic Tetrahedral Gold(I) Complexes Based on the 1,2-Bis(diphenylphosphino)benzene Ligand. Chem. A Eur. J. 2010, 16, 12114-12126. [CrossRef] [PubMed]

27. Osawa, M.; Aino, M.A.; Nagakura, T.; Hoshino, M.; Tanaka, Y.; Akita, M. Near-unity thermally activated delayed fluorescence efficiency in three- and four-coordinate $\mathrm{Au}(\mathrm{I})$ complexes with diphosphine ligands. Dalton Trans. 2018, 47, 8229-8239. [CrossRef] [PubMed] 
28. Osawa, M.; Yamayoshi, H.; Hoshino, M.; Tanaka, Y.; Akita, M. Luminescence color alteration induced by trapped solvent molecules in crystals of tetrahedral gold(I) complexes: Near-unity luminescence mixed with thermally activated delayed fluorescence and phosphorescence. Dalton Trans. 2019, 48, 9094-9103. [CrossRef] [PubMed]

29. Liu, C.Y.; Wang, H.F.; Ren, Z.G.; Braunstein, P.; Lang, J.P. Fine-Tuning of Luminescence through Changes in $\mathrm{Au}-\mathrm{S}$ Bond Lengths as a Function of Temperature or Solvent. Inorg. Chem. 2019, 58, 8533-8540. [CrossRef] [PubMed]

30. Di, D.; Romanov, A.S.; Yang, L.; Richter, J.M.; Rivett, J.P.H.; Jones, S.; Thomas, T.H.; Abdi Jalebi, M.; Friend, R.H.; Linnolahti, M.; et al. High-performance light-emitting diodes based on carbene-metal-amides. Science 2017, 356, 159-163. [CrossRef]

31. Hamze, R.; Shi, S.; Kapper, S.C.; Muthiah Ravinson, D.S.; Estergreen, L.; Jung, M.C.; Tadle, A.C.; Haiges, R.; Djurovich, P.I.; Peltier, J.L.; et al. "Quick-Silver" from a Systematic Study of Highly Luminescent, Two-Coordinate, d 10 Coinage Metal Complexes. J. Am. Chem. Soc. 2019, 141, 8616-8626. [CrossRef] [PubMed]

32. Fernandez-Cestau, J.; Bertrand, B.; Blaya, M.; Jones, G.A.; Penfold, T.J.; Bochmann, M. Synthesis and luminescence modulation of pyrazine-based gold(III) pincer complexes. Chem. Commun. 2015, 51, 16629-16632. [CrossRef] [PubMed]

33. To, W.P.; Zhou, D.; Tong, G.S.M.; Cheng, G.; Yang, C.; Che, C.M. Highly Luminescent Pincer Gold(III) Aryl Emitters: Thermally Activated Delayed Fluorescence and Solution-Processed OLEDs. Angew. Chem. Int. Ed. 2017, 56, 14036-14041. [CrossRef] [PubMed]

(C) 2019 by the authors. Licensee MDPI, Basel, Switzerland. This article is an open access article distributed under the terms and conditions of the Creative Commons Attribution (CC BY) license (http://creativecommons.org/licenses/by/4.0/). 